\title{
INHIBITION OF BLASTOCYST OUTGROWTH IN VITRO BY SERUM FROM MICE WITH ASCITES TERATOMA
}

\author{
G. R. DUNN* \\ Institute of Animal Genetics, West Mains Road, Edinburgh EH9 $3 \mathcal{F N}$
}

(Received 2nd November 1973)

\begin{abstract}
Summary. Mouse blastocysts cultured in medium supplemented with mouse serum attach to the culture vessel and the trophoblast proliferates as a sheet of cells. In medium supplemented with serum from a mouse bearing an ascites teratoma, such outgrowth in vitro does not occur. This inhibition is due to a change in the serum but does not involve cytolytic antibody.
\end{abstract}

The proliferation of trophoblast from the mouse blastocyst in vitro has been analysed by Gwatkin (1966a, b) and Gwatkin \& Meckley $(1965,1966)$. This outgrowth occurs when blastocysts are cultured in Brinster's medium (Brinster, 1965) supplemented with fetal calf serum. The present work was undertaken to determine if this outgrowth would also occur when either normal mouse serum or serum from mice with ascites teratomata was used. This tumour was chosen since its ascites form is composed of embryoid bodies, groups of cells morphologically similar to early mouse embryos (Stevens, 1960).

All sera were collected by killing mice with chloroform and withdrawing blood by heart puncture. The blood was allowed to clot at $4^{\circ} \mathrm{G}$ for $12 \mathrm{hr}$, after which it was centrifuged, and the serum was decanted. All sera were stored at $-20^{\circ} \mathrm{C}$ until used. Sera were not pooled within groups and several different samples of sera of most types were tested. Since there were no differences within groups, all data have been combined in Tables 1 and 2 .

Embryos for all assays were of the randomly bred Q strain. Phosphate-buffered saline (PBS) was used to flush blastocysts from the uterine horns of mated females 76 to $80 \mathrm{hr}$ after a copulation plug was found. Blastocysts were washed twice in PBS and held in Brinster's medium without serum at $37^{\circ} \mathrm{C}$ under $5 \%$ $\mathrm{CO}_{2}$ and $95 \%$ air until they were cultured.

Culture media were prepared immediately before use by adding serum to Brinster's medium in the desired concentration. All media were filtered through $2 \cdot 2-\mu \mathrm{m}$ Millipore filters after the addition of the serum. Drops of media $(0 \cdot 1 \mathrm{ml})$ were placed under paraffin oil in Falcon plastic Petri dishes. One blastocyst was cultured per drop under $5 \% \mathrm{CO}_{2}$ and $95 \%$ air at $37^{\circ} \mathrm{C}$ in a continuous gas-flow incubator.

Cultures were examined daily for 8 days for outgrowth of trophoblast.

* Present address: Gerontology Research Center, Baltimore City Hospitals, Baltimore, Maryland 21224, U.S.A. 
Preliminary experiments showed this to be the period of maximal outgrowth in media supplemented with $5 \%$ fetal calf serum.

The line 6050 ascites teratoma (Jackson Laboratory, Bar Harbor, Maine) was carried in strain $129 / \mathrm{Sv}-S l C P$ male mice. It was maintained by intraperitoneal injection of ascites fluid containing embryoid bodies into a new host every 24 days. Sera from tumour-bearing mice were collected at the time of tumour transfer.

Table 1. Outgrowth of mouse blastocysts in media containing $5 \%$ normal mouse serum

\begin{tabular}{l|c|c}
\hline $\begin{array}{c}\text { Serum } \\
\text { source }\end{array}$ & $\begin{array}{c}\text { Days } \\
\text { post coitum }\end{array}$ & $\begin{array}{c}\text { No. of blastocysts showing } \\
\text { outgrowth/total no. of blastocysts }\end{array}$ \\
\hline $129 *$ & - & $22 / 24$ \\
$\mathrm{Q}$ & 3 & $7 / 10$ \\
$\mathrm{Q}$ & 4 & $6 / 10$ \\
$\mathrm{Q}$ & 5 & $9 / 10$ \\
C57BL/6 & 10 & $7 / 13$ \\
C57BL/6 & 15 & $11 / 12$ \\
C3Hf & 19 & $11 / 12$ \\
\hline
\end{tabular}

$\chi^{2}=10.5$; d.f. $=6$; not significant.

* This was the only male source used.

Table 2. Outgrowth of mouse blastocysts in sera from normal and tumour-bearing mice

\begin{tabular}{l|c|c|c}
\hline \multicolumn{1}{c|}{ Serum } & $\%$ Concentration & Treatment & $\begin{array}{c}\text { No. of blastocysts showing } \\
\text { outgrowth/total no. of blastocysts }\end{array}$ \\
\cline { 2 - 3 } FCS & 5 & - & $24 / 32$ \\
& 5 & $+\mathrm{C}$ & $9 / 10$ \\
nMS & 5 & - & $32 / 35$ \\
& 5 & $+\mathrm{C}$ & $11 / 12$ \\
& 5 & HI & $15 / 15$ \\
TS & 5 & HI C & $10 / 10$ \\
& 10 & - & $16 / 22$ \\
& 5 & - & $1 / 23$ \\
nMS+TS & 5 & -C & $6 / 22$ \\
& 5 & HI & $4 / 22$ \\
& $5+2 \cdot 5$ & - & $0 / 9$ \\
& $5+5$ & - & $0 / 11$ \\
\hline
\end{tabular}

FCS = Fetal calf serum; nMS = normal mouse serum; $T S=$ teratomabearing mouse serum; $\mathrm{C}=5 \% 1 / 10$ dilution of guinea-pig serum; $\mathrm{HI}=$ heat-inactivated serum.

Freeze-dried guinea-pig serum diluted 1:9 was used as the source of complement. The reconstituted diluted serum was added to Brinster's medium to a final concentration of $5 \%$.

Sera were inactivated in a water-bath at $56^{\circ} \mathrm{C}$ for $30 \mathrm{~min}$.

Table 1 gives the results of culturing blastocysts in media containing $5 \%$ normal mouse serum. There was no effect of strain, sex, or state of pregnancy 
on outgrowth of $Q$ blastocysts, nor was there any difference between normal mouse serum and fetal calf serum.

Table 2 gives the data for culturing $Q$ blastocysts in medium containing sera from mice with an ascites teratoma and the relevant controls. In all cases, the majority of blastocysts did not grow out in medium supplemented with serum from a tumour-bearing mouse. Those which did consisted of only a few cells which were not flattened on the bottom of the culture dish but were rounded and distinctly different from the control cells. Mixing normal mouse serum with serum from tumour-bearing animals did not correct this inhibition of outgrowth.

The results presented here demonstrate that normal mouse serum is as effective as fetal calf serum for supporting blastocyst outgrowth. A macromolecular factor and several amino acids in fetal calf serum have been shown to be required for outgrowth (Gwatkin, 1966a, b). Presumably, the same amino acids and a similar macromolecule are present in normal mouse serum without regard to differences in the composition of the serum due to strain, sex, or pregnancy.

The presence of an ascites teratoma causes some change in the serum of the host such that outgrowth of blastocysts can no longer occur. This inhibitory factor is not complement-dependent, demonstrating that cytolytic antibody is not involved. The factor is, however, produced either by the tumour or by the host animal in response to the presence of the tumour. This is shown by the mixing experiments summarized in Table 2 ; the presence of normal serum did not block the inhibitory effect of the serum from mice with ascites teratomata. These results were not due to the increased serum concentration since $10 \%$ normal mouse serum supported outgrowth.

This work was supported by a Lalor Foundation grant to the author and a Ford Foundation grant to Dr Anne McLaren. The line 6050 ascites teratoma was obtained from Dr L. G. Stevens, Jackson Laboratory, Bar Harbor, Maine, U.S.A.

\section{REFERENCES}

BRINSTER, R. L. (1965) Studies on the development of mouse embryos in vitro. IV. Interaction of energy sources. F. Reprod. Fert. 10, 227.

Gwatkin, R. B. L. (1966a) Defined media and development of mammalian eggs in vitro. Ann. N.Y. Acad. Sci. 139, 79.

Gwatkin, R. B. L. (1966b) Amino acid requirements for attachment and outgrowth of the mouse blastocyst in vitro. J. cell. Physiol. 68, 335.

Gwatkin, R. B. L. \& Meckley, P. E. (1965) In vitro culture of mouse ova beyond the blastocyst stage: effect of substrate and medium components. F. Cell Biol. 27, 136A.

Gwatkin, R. B. L. \& Meckley, P. E. (1966) Chromosomes of the mouse blastocyst following its attachment and outgrowth in vitro. Annls Med. exp. Biol. Fenn. 44, 125.

Stevens, L. G. (1960) Embryonic potentiality of embryoid bodies derived from a transplantable testicular teratoma of the mouse. Devl Biol. 2, 285. 